\title{
PELATIHAN BAHASA INGGRIS TENTANG COMMUNICATIVE CONVERSATION BAGI OMK (ORANG MUDA KATOLIK) DI PAROKI ROH KUDUS TOMOHON
}

\author{
Jeane Tuilan \\ Jurusan Pendidikan Bahasa Inggris, Fakultas Bahasa dan Seni, UNIMA \\ jeanetuilan@unima.ac.id
}

\begin{abstract}
This service intends to improve the OMK's skills in constructing the communicative conversation and to increase the quantities of the members that interest with this service's activity that can promote Tomohon's tourism. This service was conducted in center of Tomohon, September 19th up to September 21th 2016. The subject was members of youth catholic community (OMK/Orang Muda Katholik) of Paroki Roh Kudus Tomohon, for the first meeting consisted of 14 members and then increase up to 20 members. The members mostly are students in Senior High School and Universities. The training materials were given through lecturing, drill, questioning and practicing. The finding shows that teaching in this service using orientations, drills, feedback and continuation improves the OMK (Orang Muda Katholik) skills in constructing the communicative conversation and increase the quantities of the members that interest with this service's activity. The members improved their skills after the service and practiced the materials better than before. The quantities of the members increased from 14 members up to 20 members. These indicate that the purpose of this service is success. The members expected to continue giving more training in the future. Based on the finding, it is suggested that English Lecturers of Universities should consider to do more service's activities to improve our Young generation's skills in order to promote our tourism to foreigners.
\end{abstract}

Keywords: Questioning, orientations, drills, feedback and continuation..

\section{PENDAHULUAN}

Saat ini persaingan global diberbagai bidang menuntut penguasaan kompetensi keterampilan (skill) dan akademik yang memadai serta dapat dipertanggungjawabkan. Dalam dunia pendidikan nasional Indonesia bermacam-macam upaya telah dilaksanakan sebagai persiapan untuk menghadapi persaingan global tersebut terutama untuk menghasilkan sumber daya manusia yang mampu bersaing dalam dunia pendidikan maupun dunia kerja. Selain upayaupaya yang dilakukan oleh pemerintah seperti wajib belajar dan tersedianya sarana pendidikan formal, pemerintah juga mendukung dan mengupayakan adanya kegiatankegiatan yang dilakukan secara non-formal dari berbagai pihak, antara lain dengan mencanangkan program-program yang sifatnya meningkatkan mutu pendidikan dan pengelolaan bertaraf international. Komitmen ini sebenarnya memiliki implikasi dan konsekuensi yang besar bagi sekolah ataupun lembaga-lembaga pendidikan baik formal maupun non-formal dan organisasiorganisasi kemasyarakatan yang ada saat ini. Banyak hal yang harus dilakukan, mulai dari pembenahan fasilitas, perbaikan kurikulum, peningkatan mutu dalam pengelolaan administrasi dan akademik, serta yang paling mendasar adalah peningkatan kemampuan Sumber Daya Manusia itu sendiri dalam menjalankan dan mendukung komitmen dan tujuan bersama. 
Peningkatan kualitas Sumber Daya Manusia dapat diaplikasikan dalam berbagai bidang, salah satunya dalam penguasaan bahasa asing, terutama bahasa Inggris. Hal ini didasari oleh berbagai pertimbangan di mana berlakunya standar mutu bertaraf internasional, pemerintah dan lembaga-lembaga yang terlibat di dalamnya, telah berkomitmen untuk meningkatkan standar yang ada dari mutu lokal menjadi mutu yang dapat bersaing secara internasional sehingga dapat mendukung kinerja dalam mencapai komitmen dan tujuan lembaga-lembaga pendidikan maupun pemerintahan.

Di era ini, penguasaan bahasa Inggris sangat diperlukan untuk mempermudah para wisatawan ataupun warga asing yang ingin menanamkan modal di Indonesia, karena bahasa Inggris menjadi bahasa internasional yang dimiliki dunia saat ini. Kemajuan maupun kelebihan suatu negara atau lebih khusus satu daerah dapat dengan mudah dipromosikan ataupun diunggulkan ke negara-negara luar dengan menggunakan bahasa Inggris. Dalam rangka meningkatkan kualitas berbahasa Inggris yang lebih baik pemerintah telah memasukkan bahasa Inggris menjadi salah satu mata pelajaran/mata kuliah dalam pendidikan formal yang ada. Selain dalam pendidikan formal, bahasa Inggris juga dapat dipelajari lewat pendidikan non-formal seperti mengikuti kursus dan pelatihan yang tersedia.
Pelatihan bahasa Inggris merupakan salah satu upaya yang dapat dilakukan untuk membantu pemerintah terutama masyarakat dalam peningkatan kualitas berbahasa Inggris. Oleh karena itu, penulis sebagai seorang dosen dalam mendukung upaya pemerintah, telah melaksanakan pelatihan bahasa Inggris kepada masyarakat khususnya untuk Orang Muda Katholik (OMK) yang ada di Paroki Roh Kudus Tomohon di kota Tomohon.

Tomohon adalah salah satu kota kecil yang ada di Sulawesi Utara. Tomohon merupakan kota yang memiliki keunggulan yang dapat dibanggakan oleh masyarakatnya. Keunggulan-keunggulan tersebut dapat terlihat dalam beberapa bidang salah satunya adalah dalam bidang pariwisata. Pariwisata merupakan sarana yang dimiliki untuk menunjukkan kepada dunia akan keindahan alam Indonesia yang tidak kala bersaing dengan yang ada di negara-negara lain. Tomohon pada khususnya memiliki beberapa objek pariwisata yang patut di unggulkan seperti; Gunung Lokon, Gunung Mahawu, Danau Linow, Air Terjun Tumimperas di Pinaras, Perkampungan Bunga, Hutan wisata Lahendong, Air Terjun Tapahan Telu Tinoor, Bukit Inspirasi Tomohon, Anyaman Bambu di Kinilow, Gereja Sion, Pasar Tradisional Tomohon, Eko wisata di Desa Rurukan, Jalan Salib, Rumah Panggung Kayu, Bukit Temboan, Waruga dan Pagoda Ekayana. Dan yang menjadi event pariwisata yang diunggulkan adalah 
kegiatan Tomohon International Flower Festival yang diselenggarakna tiap 2 tahun sekali. Kota Tomohon setiap tahun juga mengadakan pawai untuk memperingati hari kemerdekaan Indonesia pada tanggal 17 Agustus dan pawai tersebut menarik wisatawan untuk menyaksikan pawai pertunjukan Drumband/Marchingband serta atraksi budaya lainnya. Dengan banyaknya objek wisata dan events yang ada di Tomohon yang mendapat perhatian dari para wisatawan, perlu adanya pelatihanpelatihan bahasa Inggris guna meningkatkan kemampuan SDM lokal dalam berbahasa Inggris baik SDM yang terlibat langsung dalam event itu maupun SDM yang tinggal di sekitar objek-objek wisata.

Dari hasil pengamatan pada waktu pelatihan berlangsung, keterampilan berbahasa Inggris yang dimiliki peserta sudah terbilang cukup dan mampu berbahasa Inggris secara komunikatif. Walaupun para peserta telah memiliki kemampuan seperti itu sebaiknya pelatihan-pelatihan berbahasa Inggris harus terus diadakan agar kemampuan mereka juga dapat terus ditingkatkan. Secara kualitas pelatihan ini membantu peserta dalam pemilihan vocabulary dan penyusunan kalimat yang mudah dipahami dan peserta mampu menggunakan teknik berkomunikasi dengan baik. Sedangkan secara kuantitatif diharapkan para peserta dapat mengajak lebih banyak lagi Orang Muda Katolik (OMK) yang sadar akan pentingnya pelatihan ini untuk mempromosikan pariwisata di Tomohon.
Maka dari itu, pelatihan Bahasa Inggris Komunikatif ini bisa berjalan sesuai dengan yang diharapkan bahkan cukup berhasil dalam rangka peningkatan keberanian, kemampuan dan keterampilan peserta Orang Muda Katolik (OMK) di Paroki Roh Kudus Tomohon.

Masalah yang menjadi prioritas dalam pengabdian kepada masyarakat ini adalah: Pelatihan Bahasa Inggris secara komunikatif meliputi pemilihan vocabulary, penyusunan kalimat dan teknik berkomunikasi, serta pada awalnya menjangkau para orang muda yang lebih memilih kegiatan-kegiatan olah raga ataupun musik dibandingkan mengikuti pelatihan-pelatihan dalam peningkatan kemampuan berbahasa Inggris.

Kegiatan pelatihan berbahasa Inggris komunikatif ini memiliki tujuan: 1) meningkatkan keterampilan Orang Muda katolik dalam hal penyusunan kalimat yang mudah dipahami. 2) meningkatkan jumlah Orang Muda Katolik yang berminat mengikuti pelatihan bukan hanya mereka yang terlibat langsung dalam kegiatankegiatan yang ada tetapi mampu menjangkau Orang Muda Katolik (OMK) lainnya yang tinggal di sekitar objek-objek pariwisata yang ada di Tomohon.

Kegiatan pengabdian kepada masyarakat ini sangat bermanfaat bagi para peserta yaitu Orang Muda Katolik (OMK) paroki Roh Kudus Tomohon sebagai sasaran kegiatan pelatihan, setelah mereka mengikuti pelatihan ini tentu mereka 
merasa lebih percaya diri karena adanya peningkatan yang mereka peroleh dalam berbahasa Inggris secara komunikatif. Bagi pemberi materi, dosen pendidikan Bahasa Inggris tentu memiliki pengalaman tambahan dalam merencanakan, melaksanakan dan mengamati kegiatan yang diselenggarakan untuk masyarakat, yang sudah tentu berbeda dengan kegiatan dosen sehari-hari mengajar mahasiswa di kampus. Bagi lembaga, Fakultas Bahasa dan Seni Universitas Negeri Manado, kegiatan ini merupakan upaya memberi peluang bagi salah satu tenaga pengajarnya untuk melaksanakan salah satu dari Tri Darma Perguruan Tinggi.

Cara memecahkan masalah dalam pelatihan ini yaitu alternatif pertama adalah pengenalan bagaimana memilih dan menggunakan vocabulary yang tepat, kemudian diteruskan dengan menyusun kosakata itu menjadi kalimat yang bermakna, kalimat bermakna tidak cukup tentu harus diimbangi dengan teknik berkominikasi yang mudah dipahami, misalnya dengan cara take turning- kapan waktu tepat untuk mengambil alih percakapan, kata dan kalimat yang mana yang dianggap tepat untuk diungkapkan, kapan tidak harus menjawab dan lain sebagainya.

\section{METODE PENGABDIAN}

Para wisatawan dan masyarakat umum menjadi sasaran kegiatan para peserta pelatihan yang berjumlah 20 orang 38 mereka adalah para pelaku pariwisata di kota Tomohon, sehingga sangat strategis kalau mereka dilibatkan secara langsung dalam mengantisipasi perkembangan kepariwisataan di kota Tomohon.

\section{Pembuka}

Sebuah aktivitas seperti pengabdian kepada masyarakat diawali dengan pembukaan secara resmi oleh Pembantu Dekan 1 bersama pastor Paroki Roh Kudus Tomohon Pst. Paul Salabia, Pr, yang juga disaksikan oleh beberapa pengurus Organisasi Mahasiswa Katolik (OMK) Paroki Roh Kudus Tomohon. Dalam kesempatan itu, disampaikan maksud dan tujuan kegiatan, perkenalan dengan pemberi materi serta pimpinan dari Fakultas Bahasa dan Seni, Universitas Negeri Manado yang diwakili oleh Pembantu Dekan 1. Selain perkenalan diri dan penyampaian tujuan serta manfaat kegiatan sekilas disampaikan juga tentang brainstorming kemampuan berbahasa para peserta, dengan menggunakan S-R method. Metode S (Stimulus) dan $\mathrm{R}$ (Response) sangatlah ampuh untuk mengawali sebuah kegiatan berbahasa. Ungkapan yang digunakan adalah dengan sapaan Selamat malam, kemudian ditanyakan apakah bisa diterjemahkan dengan good night dan beberapa ungkapan seperti nice to meet you dan don't mention it. Hasil dari Stimulus pada ungkapan good night oleh peserta kemudian merespon dengan menyatakan boleh menggunakan good night dan 
sebagian besarnya merespon tidak boleh menggunakan good night. Dosen sebagai pemateri menjelaskan kenapa good night tidak boleh digunakan untuk menyampaikan salam selamat malam, "good night is not a greeting: it is used when leaving a place or group of people". Jadi ungkapan itu disampaikan pada saat berpisah pada malam hari/meninggalkan suatu tempat atau ungkapan yang digunakan menjelang tidur. Metode S-R ini cukup efektif untuk mengawali sebuah sesi pelatihan.

\section{Climate Setting}

Sesudah acara pembuka oleh Pembantu Dekan 1 Fakultas Bahasa dan Seni Universitas Negeri Manado, kegiatan pelatihan dilanjutkan dengan pemberian materi oleh dosen pendidikan Bahasa Inggris. Sebelum masuk pada isi materi dosen menanyakan terlebih dahulu kepada para peserta, dengan pertanyaan sederhana "what's the news?". Tidak semua peserta menjawab pertanyaan sederhana itu, tetapi beberapa peserta yang nampaknya relatif memiliki keberanian untuk menjawab pertanyaan itu mengacungkan tangan dan menjawab "fine, thank you"; "good, thank you", karena mereka menduga bahwa what's the news sama artinya dengan "apa kabar". Dalam ranah climate setting tidaklah diwajibkan memberikan jawaban yang tepat dan benar, tetapi tujuan dari penggalan pertanyaan itu adalah untuk menarik perhatian mereka supaya mereka sudah merasa in dalam kelas. Hal ini penting karena pada umumnya para peserta kursus, kuliah atau aktivitas apa saja yang melibatkan banyak orang tentu ada yang pikirannya masih melayang atau memikirkan hal lain walaupun mereka sedang duduk saat pelatihan berlangsung. Dengan pertanyaan ini, diharapkan bisa membuat mereka berkonsetrasi untuk belajar dan relatif memudahkan untuk menerima pelajaran. Hal ini merupakan situasi dimana dosen sengaja melontarkan pertanyaan seperti itu untuk menata keadaan setting the climate of learning process.

\section{Training Materials}

Pelatihan berlangsung selama 3 hari dengan topik yang disajikan dalam dialogdialog singkat antara lain:

a. Introduction and Small Talk

- Formal Greetings

- Informal Greetings and Farewells

- Formal Introductions

- Informal Introductions

- What Time is it?

- A Telephone Call

- Can You Say That Again?

- Coincidences

- Weather Report

b. Around Town

- Ordering a Meal

- At the Doctor's Office

- Asking Direction

- Calling for Help

- At the Supermarket 
- Running Errands

- At the Post office

- Catching Up after Class

- Shopping

- Transportation

c. Past times and Activities

- How Old Are you?

- Ate the Movies

- What Are You Good at?

- What's Your Favorite Sport?

- A Night at Theater

- Taking a Vacation

- $\quad$ At the Pet Store

- Giving Your Opinion

- Hobbies

- Weddings

- Giving advice

\section{Training Method}

Menurut O'Galperin (1979), seorang pakar pendidikan, dalam buku yang ditulis oleh Rooijakkers (1991) yang berjudul Mengajar dengan Sukses disebutkan bahwa demi keberhasilan melakukan proses pembelajaran untuk masyarakat, baik masalah knowledge atau skill, lebih diutamakan skill, seorang dosen hendaknya memulai dengan langkah-langkah sebagai berikut: orientation, drill, feedback dan continuation.

Pada tahap orientation seorang dosen di harapkan mampu menjelaskan halhal apa saja yang hendaknya perlu diketahui dan diajarkan olehnya kepada peserta didik. Penjelasan ini menyangkut topik, teknik mengajar dan evaluasi serta output apa 40 yang hendak dicapai. Penjelasan dapat diawali dengan menanyakan sesuatu yang akan mengaktifkan pemahaman mereka tentang materi yang akan diajarkan, pemberian definisi dan uraian yang menghubungkan materi dengan kenyataan yang ada di masyarakat.

Pada tahap drill, dosen memberikan latihan-latihan terhadap apa yang sudah dibahas sebelumnya pada tahap orientation. Latihan bisa dilakukan secara individu, kelompok ataupun yang melibatkan seluruh peserta pelatihan. Dalam pelatihan ini peserta dimintakan untuk membuat dialog baru berdasarkan contoh dialog singkat yang diberikan. Dialog yang baru disusun berdasarkan situasi yang ada yang berhubungan dengan tujuan. Kemudian dialog tersebut dipraktekkan.

Pada tahap feedback diberikan 'umpan balik' terhadap semua kegiatan yang telah dilaksanakan pada tahap sebelumnya. Ada dua model umpan balik yaitu reward dan remedial. Reward berupa pujian apabila peserta dalam pelatihan ini sudah mampu melakukan latihan dengan baik, sehingga tahap berikutnya segera dilanjutkan. Apabila peserta masih menunjukkan adanya masalah dan kesulitan, baik pelafalan kata, penyusunan kalimat, maka diberikan remedial. Pengulangan tahap orientasi bisa dilaksanakan agar latihan yang diberikan bisa mencapai kemajuan. Apabila dalam tahap feedback sudah mengindikasikan adanya pemahaman dan kemajuan, maka tahap selanjutnya bisa dilanjutkan. 
Pada tahap continuation diharapkan ketiga tahap sebelumnya telah selesai secara tuntas. Tahap ini merupakan evaluasi dari tahapan orientasi, latihan dan umpan balik, sehingga topik selanjutnya dapat diteruskan. Topik baru tentu melalui tahapan-tahapan seperti sebelumnya.

\section{Evaluasi}

Tahapan evaluasi bisa dilakukan dalam dua bagian yaitu: (1) setelah setiap topik berakhir. Hal ini dilakukan dengan tujuan untuk memberikan feedback atas materi yang baru saja diajarkan, dan memberikan gambaran tentang rencana pada topik berikutnya. (2) pada pertemuan terakhir. Hal ini dilakukan untuk memberikan kesempatan pada peserta untuk mendemonstrasikan kemampuan yang telah dicapai sehingga bisa disimpulkan keberhasilan pelatihan ini.

\section{HASIL DAN PEMBAHASAN}

Untuk mengetahui tingkat keberhasilan yang dicapai dalam kegiatan pembelajaran ini, tentu telah diadakan evaluasi. Evaluasi dilaksanakan dengan tujuan yaitu: (1) untuk mengetahui capaian keberhasilan peserta dalam menyerap materi yang diajarkan; (2) kesesuaian materi dengan kebutuhan peserta pelatihan, keefektifan metode pengajaran dilihat dari pemahaman peserta dan evaluasi sekaligus menjadi refleksi bagi peserta terutama bagi dosen.

Dari penjelasan-penjelasan di atas terkait dengan evaluasi dalam pelatihan ini didapatkan hasil: (1) peserta dengan antusias menyimak dan memahami bahan ajar. Ini dapat terlihat dengan hasil latihan yang menunjukan adanya peningkatan pemahaman dan peningkatan keterampilan dalam penguasan materi. Jumlah peserta bertambah dari 14 orang menjadi 20 orang. (2) terdapat sedikit kendala karena materi yang ada dalam handout tidak dapat mengcover semua yang dibutuhkan. Hal ini disebabkan karena variasi kemampuan dan kebutuhan mereka yang tinggi sehingga bukan menjadi hal yang mudah menyeragamkan bahan ajar untuk semua peserta. (3) dari hasil yang didapat ternyata dapat terlihat adanya perbedaan penerapan metode mengajar yang digunakan dosen sehari-hari di universitas dengan metode pengajaran di pelatihan. Dalam pelatihan metode dilakukan lebih non-formal atau santai disesuaikan dengan siapa peserta yang dihadapi. (4) merupakan suatu hal baik jika dosen melakukan refleksi atas tahap-tahap yang sudah dilaksanakan. Hal ini dimaksudkan untuk mengetahui keberhasilan mengajar secara tuntas pada setiap tahap yang ada. Evaluasi keberhasilan bagi seorang dosen bukan saja ditentukan oleh selesainya pemberian materi pelatihan, tetapi juga adanya gambaran tentang pemahaman yang berhasil dicapai oleh peserta pelatihan serta mengetahui apa penilaian dari peserta tentang pelatihan yang telah dilaksanakan. 


\section{KESIMPULAN DAN SARAN}

\section{Kesimpulan}

Kesimpulan tentang Pengabdian

Kepada Masyarakat dalam bentuk kegiatan Pelatihan Bahasa Inggris tentang communicative conversations telah memberikan peluang kepada masyarakat khususnya Orang Muda Katolik (OMK) Paroki Roh Kudus di Tomohon untuk meningkatkan pengetahuan dan keterampilan dalam berkomunikasi menggunakan bahasa Inggris. Dengan kegiatan-kegiatan yang ada dalam pengabdian kepada masyarakat para Dosen diberikan kesempatan untuk mengamalkan ilmunya di masyarakat dalam kaitan dengan melaksanakan salah satu dari Tridharma Perguruan Tinggi. Bagi institusi, Fakultas Bahasa dan Seni Universitas Negeri Manado hal ini merupakan dukungan yang mulia untuk berperan dalam pembangunan manusia Indonesia, khususnya peningkatan kemampuan dan keterampilan berbahasa Inggris.

\section{Saran}

Masalah bahasa Inggris tidak akan bisa dituntaskan dalam waktu yang singkat. Salah satu kata bijak berbahasa Inggris mengatakan "there is not shortcut to master English". Oleh karena itu kelanjutan program ini perlu direncanakan dan dipertimbangkan ke depan agar tetap tercipta situasi konsisten yang memiliki komitmen mengajarkan ilmu dan keterampilan kepada masyarakat luas, demi kemajuan masyarakat, negara dan bangsa.

\section{UCAPAN TERIMA KASIH}

Dosen mengucapkan banyak terima kasih kepada Rektor Unima Prof. Dr. Julyeta P.A Runtuwene, M.S., Ketua Lembaga Pengabdian Masyarakat Unima Prof. Dr. Revelson A. Mege, M.S., serta organisasi Orang Muda Katholik (OMK) Paroki Roh Kudus dalam pemberian dukungan untuk terlaksananyan kegiatan pelatihan ini. Terima kasih yang tulus juga kepada Dekan FBS Unima Dr. Donal M. Ratu, M.Hum., Pembantu Dekan I FBS Unima, Dr. Ignatius Javier Tuerah, M.Pd., yang telah membuka pelatihan ini, juga kepada pastor Paroki Roh Kudus Tomohon P. Paul Salabia, Pr atas ijin yang diberikan pada pelatihan ini. Secara khusus sahabat saya Jeane Mantiri S.AB., M.A.P yang mendukung saya dalam proses penyusunan laporan pelatihan ini.

\section{KEPUSTAKAAN}

Klein, wolfgang. 1985. Second Language Acquisition. Oxford: Oxford University Press.

Rooijakers, Ad. 1991. Mengajar Dengan Sukses: Petunjuk Untuk Merencanakan dan Menyampaikan Pengajaran. Jakarta: Grasindo.

Richards J. C. and Theodore S. Rodger, 2001. Approaches and Methods in Language Teaching. Cambridge: Cambridge University Press. 